\title{
O currículo do Curso Técnico em Agropecuária: subver- tendo a concepção de grade curricular
}

\author{
Flávia Moreira Barroca de Barros \\ Ana Louise de Carvalho Fiúza \\ Maria de Lourdes Mattos Barreto \\ José Ambrósio Ferreira Neto \\ Universidade Federal de Viçosa
}

\footnotetext{
Correspondência:

Flávia Moreira Barroca de Barros

Universidade Federal de Viçosa

Campus Florestal

35690-000 - Viçosa/MG

E-mail: fmbarros@ufv.br
}

\section{Resumo}

Este artigo analisa os fatores que influenciaram a composição do currículo trabalhado no Curso Técnico em Agropecuária da Central de Ensino e Desenvolvimento Agrário de Florestal ao longo de sua existência. Buscamos compreender a forma como se dão as modificações no currículo do curso, identificando as mudanças de temas trabalhados na formação do profissional, as fontes de influência das transformações ocorridas, os atores envolvidos, as demandas advindas da sociedade e, ainda, como as modificações curriculares são incorporadas na prática de ensino dos professores. Foi realizado um levantamento de dados primários e secundários. No levantamento dos dados primários, utilizamos documentos do Curso Técnico em Agropecuária do arquivo da escola e realizamos entrevistas com os professores do curso, identificando suas concepções sobre o contexto relativo ao processo de modificações do currículo. No levantamento de dados secundários, foi realizada pesquisa em bibliografia especializada e nos documentos legais da área da educação profissional. Podemos afırmar que a concepção teórica adotada neste trabalho - a qual concebe o currículo, primeiro, como uma configuração e não como algo dado, e, segundo, como um campo de forças dentro do qual os desequilíbrios entre os atores envolvidos em sua configuração estabelecem-se mediante a incontestabilidade da realidade - sustenta-se. Ou seja, não é possível nem que o Estado imponha leis que não possam ser operacionalizadas, nem que a escola desconheça as mudanças advindas da sociedade e do Estado, nem que a sociedade deixe de adequar-se a esses novos direcionamentos.

\section{Palavras-chave}

Currículos - Técnico em agropecuária - Ensino agrícola - Educação profissional. 


\title{
The curriculum of the Technical Course in Agriculture: subverting the concept of curriculum matrix
}

\author{
Flávia Moreira Barroca de Barros \\ Ana Louise de Carvalho Fiúza \\ Maria de Lourdes Mattos Barreto \\ José Ambrósio Ferreira Neto \\ Federal University of Viçosa
}

Contact:

\begin{abstract}
This article analyzes the factors that have influenced the composition of the curriculum used in the Technical Course in Agriculture of the Center for Agriculture and Forrest Teaching and Development throughout its existence. We have tried to understand the way in which the modifications in the curriculum have happened, identifying the changes in themes developed during the formation of the professional, the sources of influence for the transformations that occurred, the actors involved, the demands coming from the society and, also, how curriculum modifications are incorporated into teaching practices. A survey of primary and secondary data was made. In the primary data survey we used school archive documents from the Technical Course in Agriculture, and we carried out interviews with teachers involved in the course, identifying their views on the context associated to the process of modifying the curriculum. The secondary data survey included a research into the specialized literature and in the legal documentation for the area of professional education. We can say that the theoretical viewpoint adopted in the present work - which conceives curriculum first as a configuration, and not as something given and, second, as a field of forces within which the imbalances between the actors involved in its configuration are established through the indisputability of reality - is here upheld. In other words, it is not admissible that the State should impose laws that cannot be implemented, nor that the school should ignore the changes coming from society and the State, nor that society should fail to adapt to these new directions.
\end{abstract}

\section{Keywords}

Curricula - Technician in agriculture - Agricultural teaching Professional education.

Favia Moreira Barroca de Barros

Universidade Federal de Viçosa

Campus Florestal

35690-000 - Viçosa/MG

E-mail: fmbarros@ufv.br 


\section{Introdução}

0 presente artigo, fruto de uma dissertação de mestrado ${ }^{1}$, apresenta uma análise acerca dos fatores que influenciam a composição do currículo desenvolvido em cursos técnicos em agropecuária. Por meio desta análise, fundamentamos a concepção do currículo como: 1) algo vivo e dinâmico, constituído por choques e embates que se estendem desde o momento de sua proposição até sua efetivação prática em sala de aula; 2) um instrumento de formação profissional, no caso de cursos técnicos, capaz de qualificar profissionais para a criação de inovações e para a resolução de problemas; 3) um instrumento de qualificação para o trabalho capaz de possibilitar que indivíduos de camadas populares galguem uma ascensão socioeconômica.

Apresentamos aqui a análise dos fatores que influenciaram a composição do currículo trabalhado no Curso Técnico em Agropecuária da Central de Ensino e Desenvolvimento Agrário de Florestal (CEDAF) ao longo de sua existência. A proposta de realização da pesquisa surgiu a partir dos questionamentos feitos sobre a formação desse técnico e os desafios que lhe são impostos na atualidade pelas novas configurações do meio rural. Desenvolvemos, neste trabalho, uma reflexão acerca dos conhecimentos que compõem o currículo do curso como espaço de disputas sociais, políticas e culturais.

Nossa pesquisa tomou como objeto de estudo o currículo do Curso Técnico em Agropecuária da CEDAF (Florestal, MG). Desde sua fundação, em 1939, a instituição teve como objetivo a preparação de profissionais voltados para o meio rural, formando, inicialmente, por meio dos ensinos primário e profissional-agrícola, capatazes, administradores de fazenda e técnicos agrícolas. No decorrer dos anos, ela passou a formar técnicos em agropecuária, chegando aos atuais Curso de Técnico em Agroindústria e Curso Técnico em Informática, que passaram

1- Dissertação apresentada no Curso de Pós-Graduação em Extensão Rural. a ser oferecidos a partir de 1999, e os cursos superiores de Tecnologia em Gestão Ambiental e de Tecnologia em Desenvolvimento de Sistemas, que são oferecidos desde 2008. Percebemos, por meio desses vários momentos da educação agrícola de Florestal, que houve uma diversificação em sua oferta de cursos, o que está em consonância com as novas configurações do meio rural, não mais exclusivamente agrícola mas, antes, em franca conexão com os centros urbanos.

Construímos como problema de investigação a busca por compreender como ocorrem as mudanças no currículo do Curso Técnico em Agropecuária, tentando identificar as fontes de influência das transformações ocorridas no currículo do curso da CEDAF, os atores envolvidos, bem como se as modificações curriculares são incorporadas na prática de ensino dos professores.

Nossas hipóteses de investigação foram as seguintes: 1) os processos de modificação do currículo nas escolas agrotécnicas dar-se-iam a partir da prática cotidiana dos professores; 2) os processos de modificação do currículo nas escolas agrotécnicas dar-se-iam a partir dos direcionamentos legais; 3) os processos de modificação do currículo nas escolas agrotécnicas dar-se-iam a partir das influências dos direcionamentos que emergem da sociedade; 4) os processos de modificação do currículo nas escolas agrotécnicas dar-se-iam a partir da combinação entre os direcionamentos advindos da sociedade e da legislação, estando os professores condicionados a esses direcionamentos.

A pesquisa realizada teve um caráter descritivo e foi operacionalizada a partir do levantamento de dados primários e secundários. Para o levantamento dos dados primários, foram utilizados documentos do Curso Técnico em Agropecuária arquivados na CEDAF e realizadas entrevistas com os professores do curso. No processo de levantamentos de dados secundários, foi realizada pesquisa em bibliografia especializada, como também nos documentos legais da área da educação profissional. 


\section{Marco teórico}

De acordo com Tomaz Tadeu da Silva (2007), uma definição não nos mostra o que é essencialmente o currículo, mas nos revela o que uma teoria pensa sobre ele. 0 importante é saber a quais questões uma teoria do currículo busca responder. Desse modo, a questão fundamental de toda teoria do currículo é a de saber qual conhecimento deve ser ensinado. Em resposta a essa pergunta, as diferentes teorias podem recorrer a discussões sobre a natureza humana, sobre a natureza da aprendizagem ou sobre a natureza do conhecimento, da cultura e da sociedade. É em função desses elementos que as teorias do currículo diferem. Quando tentam responder à pergunta sobre $o$ quê, elas objetivam responder sobre que tipo de pessoas querem formar, que tipo de conhecimento é importante a partir do tipo de pessoa que consideram ideal. "Qual o tipo de ser humano desejável para um determinado tipo de sociedade?" (p. 15).

Portanto, é a questão do poder que separa as teorias tradicionais das teorias críticas e pós-críticas do currículo. As teorias tradicionais pretendem ser somente teorias neutras, supostamente científicas, desinteressadas, enquanto as teorias críticas e pós-críticas argumentam que nenhuma teoria é neutra, pois está implicada em relações de poder. As teorias tradicionais concentram-se mais em questões técnicas, uma vez que aceitam mais facilmente o status quo, os conhecimentos e os saberes dominantes. Nesse sentido, o conhecimento a ser transmitido é inquestionável, sendo apenas necessário organizá-lo. As teorias críticas e pós-críticas vão além, querem saber o porquê de determinado conhecimento, e não outro, estar no currículo. As concepções críticas estão interessadas nas conexões entre saber, identidade e poder; consideram que são os conceitos utilizados por uma teoria para conceber sua realidade que a definem (SILVA, 2007).

As teorias críticas do currículo fazem uma inversão nos fundamentos das teorias tradicionais, que não se preocupam em fazer qualquer tipo de questionamento mais radical aos arranjos educacionais existentes e às formas dominantes de conhecimento, tomando o status quo como referência desejável. "Os modelos tradicionais de currículo restringiam-se à atividade técnica de como fazer o currículo" ( $p$. 30). Já as teorias críticas do currículo desconfiam do status quo, responsabilizando-o pelas desigualdades e injustiças sociais. Nas palavras de Silva, "para as teorias críticas o importante não é desenvolver técnicas de como fazer o currículo, mas desenvolver conceitos que permitam compreender o que o currículo faz" (p. 30).

Diferenciando-se da concepção crítica, temos ainda as teorias pós-críticas, que enfatizam a necessidade de percepção do multiculturalismo. Constituem-se em um movimento de reivindicação dos grupos culturais dominados para terem suas formas culturais reconhecidas e representadas na cultura nacional. Silva (2007) afirma haver uma continuidade entre a perspectiva multiculturalista e a tradição crítica do currículo. A tradição crítica chamou a atenção para as determinações de classe do currículo e o multiculturalismo apresentou outro foco de origem da desigualdade em matéria de educação e currículo, pautado nas questões de gênero, raça e sexualidade.

Dentro dessa visão político-cultural, podemos destacar a perspectiva de Jean-Claude Forquin (1993), para quem "toda educação, e em particular toda educação do tipo escolar, supõe sempre na verdade uma seleção no interior da cultura $^{2}$ e uma reelaboração dos conteúdos da cultura destinados a serem transmitidos às novas gerações” (p. 14). Essas novas gerações seriam apresentadas a determinados valores $\mathrm{e}$ princípios escolhidos por um grupo social específico, por meio do currículo. Assim, a escola

2- Segundo Forquin (1993, p. 12), o significado da palavra cultura, quando se fala da função de transmissão cultural da educação, remete essencialmente a um patrimônio de conhecimento e de competência, de instituições, de valores e de símbolos, constituído ao longo de gerações e característico de uma comunidade humana particular, definida de modo mais ou menos amplo e mais ou menos exclusivo. 
ensina uma parte restrita de tudo o que constitui a experiência coletiva, selecionando parte da cultura viva de uma comunidade humana.

Também para Silva (1990), o currículo está impregnado por relações de poder. Segundo ele, o que é escolhido como conhecimento escolar compõe uma seleção particular e arbitrária de um universo muito mais amplo de possibilidades. Tanto o conhecimento em geral como o conhecimento escolar são produtos de um processo incessante e desinteressado de busca da verdade. 0 processo de criação, seleção, organização e distribuição do conhecimento escolar, de acordo com ele, está diretamente relacionado com os processos sociais mais amplos de acumulação e legitimação da sociedade capitalista.

Para esses autores, portanto, o currículo é visto como um artefato político e cultural. Ou seja, o currículo não é um artefato inocente e neutro de transmissão desinteressada do conhecimento social. 0 conhecimento corporificado como currículo educacional não pode mais ser analisado fora de sua constituição social e histórica. 0 currículo está imbuído em relações de poder e imprime visões sociais particulares e interessadas. Dessa forma, ele é visto como uma área contestada, uma arena política. "O currículo não é um elemento transcendente e atemporal - ele tem uma história, vinculada às formas específicas e contingentes de organização da sociedade e da educação" (MOREIRA; SILVA, 1995, p. 8).

0 currículo não é simplesmente uma montagem neutra de conhecimentos que, de alguma maneira, surge nos livros e nas salas de aula de um país. Ele sempre é parte de uma seleção feita por alguém a partir da visão que algum grupo tem do que seja o conhecimento legítimo. Portanto, "ele é produzido pelos conflitos, tensões e compromissos culturais, políticos e econômicos que organizam e desorganizam um povo" (APPLE, 2000, p. 53). Segundo Grundy (1987 apud SACRISTÁN, 2000), o currículo não é um conceito, mas uma construção cultural, isto é, não se trata de um conceito abstrato que tenha algum tipo de existência fora e previamente à experiência humana. É, antes, um modo de organizar uma série de práticas educativas. (p. 14)

Os currículos também expressariam o equilíbrio de interesses e forças que gravitam em torno do sistema educativo em determinado momento; por meio deles, realizam-se os fins da sociedade no ensino escolarizado. Eles desempenham missões distintas em diferentes níveis educativos, conforme as características destes, na medida em que refletem diversas finalidades de tais níveis (SACRISTÁN, 2000). Portanto, não se podem reduzir os problemas relevantes do ensino à problemática técnica de instrumentar o currículo, pois assim estaríamos desconsiderando os conflitos de interesses que estão presentes no mesmo. 0 currículo, na forma e nos conteúdos com que se apresenta, é uma opção historicamente configurada que se consolidou dentro de determinada trama cultural, política, social e escolar, estando impregnado de valores e pressupostos aos quais é preciso decifrar. Quando o currículo é definido, está-se apresentando a concretização das funções da própria escola e o modo particular de enfocá-la em um momento histórico e social determinado, para um nível ou modalidade de educação, em uma trama institucional (SACRISTÁN, 2000).

0 currículo modela-se dentro de um sistema escolar concreto, destina-se a determinados professores e alunos, utiliza-se de determinados meios e cristaliza-se, enfim, em um contexto, que é o que dá o significado real. Portanto, segundo José Gimeno Sacristán (1995, 2000), a única teoria capaz de dar conta desses processos é a crítica, que coloca em evidência as realidades que os condicionam. Compreender o currículo como uma práxis significa aceitar que muitos tipos de ações interferem em sua configuração; que o processo ocorre dentro de certas condições concretas e em um mundo de 
interações culturais e sociais, que é um mundo construído; que essa construção não é independente de quem tem o poder para constituí-la (GRUNDY, 1987 apud SACRISTÁN, 2000, p. 21). Para que o currículo contribua para o interesse emancipatório, ele deve ser entendido como uma práxis, baseada na ação e na reflexão.

De acordo com Sacristán (2000), “o currículo pode ser visto como um objeto que cria em torno de si campos de ação diversos, nos quais múltiplos agentes e forças se expressam em sua configuração, incidindo sobre aspectos distintos" (p. 101). Para o autor, o currículo não pode ser analisado como um objeto estático, mas como a busca de um equilíbrio entre vários compromissos. Portanto, se compreendemos o currículo como algo que se constrói e se almejamos que ele não se torne uma mera reprodução de decisões e modelações implícitas, é necessária uma intervenção ativa, discutida explicitamente em um processo de deliberação aberto por parte dos agentes participantes: professores, alunos, pais, sociedade.

Sacristán (2000) interpreta o currículo como sendo construído no cruzamento de influências e campos de atividades diferenciados e inter-relacionados. Ele distingue seis momentos no processo de desenvolvimento do currículo: um currículo prescrito, um currículo apresentado aos professores, um currículo modelado pelos professores, um currículo em ação, um currículo realizado e um currículo avaliado. Segundo o autor, devemos entender o currículo no contexto em que ele se configura e nas condições em que se desenvolve, uma vez que ele é um objeto social e histórico.

Se o currículo é uma prática, significa que todos os que dela participam são sujeitos e não objetos, ou seja, são elementos ativos. Nesse processo de intervenção subjetiva, não se pode desconsiderar a dimensão política, sendo necessário questionar-se acerca da propriedade de intervir ou não, onde e em que medida. Segundo Sacristán (2000), incidiriam sobre o professor não somente as determinações a serem respeitadas, provenientes do conhecimento ou dos componentes diversos que se manifestam no currículo, mas também as obrigações em relação aos seus próprios alunos e ao meio social concreto em que vivem, o que o faz intervir devido à sua responsabilidade para com eles. Não é novidade para o pensamento pedagógico que a consciência ou o ponto de vista dos professores constituem um fator condicionante da educação e, mais especificamente, da aprendizagem dos alunos. Também existe uma preocupação da investigação pedagógica em considerar seu papel de mediadora nos processos de ensino. Portanto, para Sacristán (2000), em sua análise do desenvolvimento do currículo na prática, a ideia de mediação compreende o professor como um mediador crucial entre o currículo estabelecido e os alunos, um agente ativo no desenvolvimento curricular, um modelador dos conteúdos que se distribuem e dos códigos que estruturam esses conteúdos, delineando toda a gama de aprendizagem dos alunos.

Contudo, por ser a atividade dos professores uma ação que transcorre dentro de uma instituição, sua prática está inevitavelmente condicionada. Sua ação não é decidida no vazio, mas no contexto da realidade de um local de trabalho, em uma instituição que tem suas normas de funcionamento balizadas por uma diretriz administrativa específica, pela política curricular do governo, pela tradição que se acata sem discutir ou por outros determinantes sociais. Portanto, para o autor, não se deve enfocar de forma exagerada a importância dos professores no direcionamento do ensino. "A margem de autonomia que o sistema educativo e curricular deixa nas mãos dos professores é o campo no qual eles desenvolverão sua profissionalização" (SACRISTÁN, 2000, p. 168). 0 professor não escolhe as condições em que realiza seu trabalho, como também não tem grande margem de liberdade em desenvolvê-lo.

\section{Metodologia}

Com o objetivo de identificar os temas trabalhados na formação profıssional do técnico 
em agropecuária e também de constatar as mudanças ocorridas no currículo do curso, foi realizada uma análise acerca de suas matrizes curriculares. Selecionamos, ainda, livros de atas de reuniões do Conselho Escolar, da Comissão de Ensino, do Colegiado e do Conselho de Classe, nos quais buscamos subsídios para explicar como ocorreram as alterações nas matrizes curriculares. Inicialmente, foram relacionadas as matérias e suas respectivas cargas horárias no período compreendido entre 1972 e 2008. As disciplinas foram agrupadas por triênio, pois essa unidade de tempo permite a identificação precisa e pontual das mudanças ocorridas, uma vez que o curso tem a duração de três anos. Posteriormente, foi realizado um levantamento da carga horária total do curso, tanto da parte do ensino médio, como da parte profissionalizante do Curso Técnico em Agropecuária.

\section{Análise dos resultados}

\section{A influência da lei sobre o currículo}

Verificamos, no gráfico 1, que a carga horária total do curso tem uma tendência crescente. A partir de 2000, esse crescimento é acentuado, coincidindo com a implantação da reforma do ensino de 1996. Já a carga horária da parte profissionalizante apresenta uma tendência crescente até o ano de 1996. Porém, a partir de 1997, ela tende a diminuir. 0 inverso acontece com a carga horária do ensino médio, que apresenta um crescimento a partir de 1997. Após essas alterações, a carga horária permanece estável, mantendo-se constante a partir de 2002.

\section{Gráfico 1 - Carga horária total do curso.}

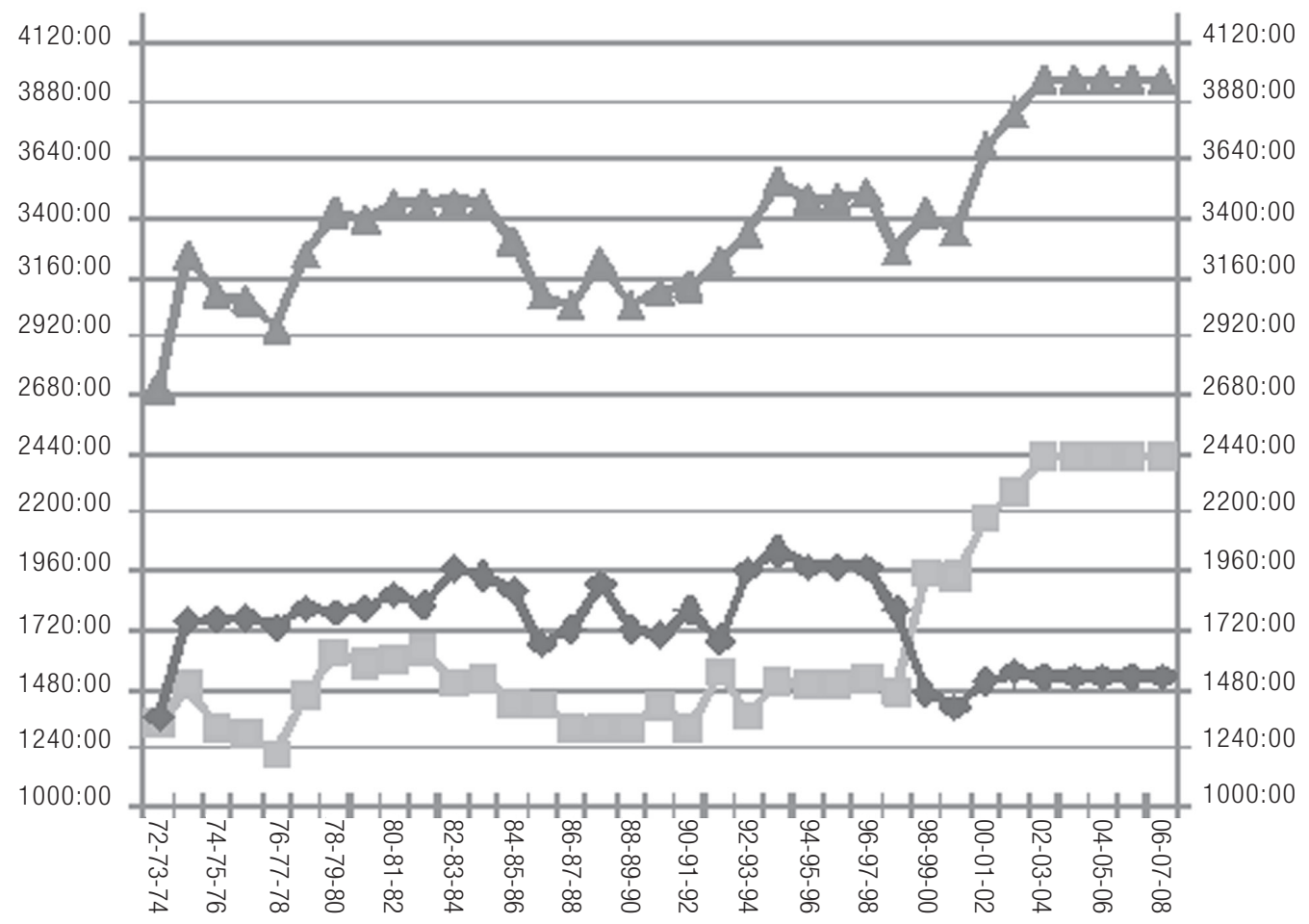


A influência da lei sobre a distribuição da carga horária no currículo fica clara por meio das leis descritas a seguir. 0 Parecer $n^{\circ}$ 45/72, vigente até a publicação da Resolução CNE/CEB 04/99 - que fixou como necessário para a habilitação de técnico do setor primário o mínimo de 2.900 horas, com a obrigatoriedade de pelo menos 1.200 horas de conteúdo profissionalizante -, foi modificado pela Lei $\mathrm{n}^{\circ}$ 9.394/96, passando a exigir o mínimo de 2.400 horas para o ensino médio e mantendo o mínimo de 1.200 horas para a área profissional de agropecuária, mas elevando para o mínimo de 3.600 horas o total do Curso Técnico em Agropecuária. Assim, houve um aumento significativo da carga horária do núcleo comum (ensino médio), forçando a uma diminuição da parte profissional.

Entretanto, é possível observar que algumas das variações que aconteceram na carga horária ao longo do curso podem ser explicadas por outros fatores. Dentre eles está o fato de os calendários escolares não terem apresentado o mesmo número de semanas letivas, havendo, assim, a modificação do módulo/aula de um ano para o outro. Há anos letivos em que o número de semanas varia entre 34, 36 e 40, e que o módulo/aula das aulas práticas varia entre 90, 60 e 50 minutos, o que pode ocasionar uma variação na carga horária. Por exemplo, uma matéria com três aulas por semana, em um ano com 34 semanas e com módulo/aula de 50 minutos, pode, em determinado ano, ter tido a carga horária de 85 horas; em outro ano, com 36 semanas, ter tido a carga horária de 90 horas; e, em outro, com 40 semanas, ter tido a carga horária de 100 horas. Ou seja, em um triênio, a carga horária total do curso pode variar em até 570 horas.

Essa explicação faz-se necessária para mostrar que pode haver alterações da carga horária do curso de um ano para outro e que esta não é determinada apenas por força da lei, havendo um espaço de autonomia para a atuação e a decisão da escola. Há a sugestão de alteração dos conteúdos e da carga horária das matérias abordadas no Curso Técnico em Agropecuária, mas também há momentos de interferência da administração superior, recomendando a inclusão de disciplinas. Outro ponto importante discutido é o aspecto legal dessas mudanças e dos objetivos reais do curso profissionalizante. A reforma de ensino imposta pela Lei $n^{\circ}$ 9.394/96 determinou que a carga horária mínima anual do ensino médio fosse de 800 horas distribuídas por um mínimo de 200 dias de efetivo trabalho escolar. Essa imposição da lei sobre o ensino médio veio a interferir na organização da parte profissional, uma vez que a obrigatoriedade de no mínimo 800 horas em cada série do ensino médio forçou uma diminuição da carga horária da parte profissional.

Por meio das transcrições feitas anteriormente, podemos inferir que há diversas influências sobre a composição da matriz curricular, tais como: a demanda dos alunos e de seus pais, a recomendação da administração superior da universidade, a interpretação dos professores acerca das necessidades dos alunos e a própria legislação vigente na época. Observamos também que os professores têm uma margem de autonomia para decidir sobre a composição do currículo, sugerindo alterações. Segundo Alves (2002), não se pode negar que, apesar do aparato jurídico, são desenvolvidas no cotidiano escolar várias atividades e experiências que não estavam previstas ou sugeridas pelos guias escolares ou pelas legislações que os cercam. Com o objetivo de confirmar a influência do cotidiano sobre o conteúdo, perguntamos aos professores se o cotidiano da sala de aula influencia nas alterações dos conteúdos de suas respectivas matérias. Segundo $81,25 \%$ dos professores, o cotidiano influencia nas alterações dos conteúdos, conforme apresentado na tabela 1 .

Os professores apontaram os seguintes fatores como sendo influentes nas alterações: o interesse dos alunos, a demanda por novas tecnologias e a troca de informações no cotidiano da sala de aula. Também quando levantamos, junto aos professores, suas opiniões quanto à necessidade de atualização do currículo, obtivemos elementos advindos de suas próprias visões de mundo sendo incorporados ao currículo: 50\% 
dos professores disseram que ele deve avançar em aspectos como bioenergia, agroecologia, legislação ambiental (normas, regulamentação), liderança, relações humanas, relações interpessoais, gerenciamento e inovações tecnológicas. Podemos inferir que há uma valorização, por parte dos professores, em relação às questões concernentes ao meio ambiente e à sustentabilidade, o que se deve às mudanças demandadas por um desenvolvimento rural mais sustentável. Eles ainda demonstraram valorizar questões relativas a atividades de gerenciamento, nas quais o técnico deve ter uma visão do processo produtivo como um todo, e também a necessidade de uma formação que permita um melhor relacionamento do técnico com as pessoas envolvidas no desenvolvimento de seu trabalho.

Tabela 1- Reconhecimento, por parte dos professores, acerca da influência do cotidiano no conteúdo da disciplina.

\begin{tabular}{l:c:c}
\hline $\begin{array}{l}\text { 0 cotidiano de sala de aula influencia } \\
\text { nas alterações de conteúdo da disciplina? }\end{array}$ & $\mathbf{N}^{\circ}$ & $\%$ \\
\hline Sim & 13 & 81,25 \\
\hline Às vezes & 3 & 18,75 \\
\hline
\end{tabular}

(Fonte: pesquisa de campo, 2008).

\section{A influência da sociedade sobre o currículo}

Um de nossos objetivos nesta pesquisa foi analisar se havia demandas advindas da sociedade e se estas são incorporadas ao currículo. Sendo assim, foi possivel verificar, junto aos documentos, como essas demandas aparecem e como os professores perceberam as demandas advindas da sociedade sobre o currículo.

Nas atas, deparamos com demandas de diversas naturezas da sociedade com relação à CEDAF. Entre elas, encontramos registros de solicitações ligadas ao ensino, tais como a de cursos para agricultores. Também observamos nos documentos a discussão sobre a abertura do Curso Técnico em Florestas, devido à demanda das empresas Belgo Mineira, Companhia Agrícola e Flo- restal (CAF) e Vale do Rio Doce. Na ata de reunião do Colegiado do dia 3 de julho de 1996, encontramos um registro da possibilidade de um convênio com o Ministério do Trabalho e o Ministério de Educação para implantar na CEDAF cursos informais de qualificação na área de ciências agrárias. Posteriormente, encontramos em outra ata de reunião de Colegiado, de 11 de maio de 2001, o relato de que a CEDAF foi, dentre as escolas vinculadas à universidade, a que teve menor índice de evasão nos cursos de qualificação.

$\mathrm{Na}$ ata do Colegiado de 11 de maio de 1999, há registros sobre convênio entre a Secretária de Estado de Educação, prefeituras da região e a CEDAF para implantação de curso superior. Essa demanda foi atendida com o oferecimento do Curso de Pedagogia para capacitar professores da rede municipal e estadual da região. Outra atividade que é tradicional na escola e que atende às demandas de capacitação por parte dos produtores é a Semana do Fazendeiro ${ }^{3}$, que já está em sua quadragésima edição. A escola também tem convênio com o Serviço Nacional de Aprendizagem Rural (SENAR), com a Empresa de Assistência Técnica e Extensão Rural (EMATER) e com sindicatos rurais em que são ministrados cursos de educação informal para atender à demanda de produtores rurais de várias regiões de Minas Gerais e suas famílias. Os dados obtidos junto à coordenação de extensão da escola nos anos de 2006, 2007 e 2008 mostraram-nos que foram oferecidos cursos com seus parceiros, atendendo às mais diversas localidades do Estado de Minas Gerais ${ }^{4}$. 0 quadro 1 ilustra a variedade de cursos que são oferecidos nessas parcerias com a escola:

\footnotetext{
3- Também denominada Semana do Produtor Rural.

4- Cidades em que foram oferecidos cursos de extensão: Abaeté, Aiuroca, Alfredo de Vasconcelos, Almenara, Alvinópolis, Antônio Dias, Araçuaí, Araxá, Baependi, Barbacena, Bom Jardim de Minas, Brás Pires, Braúnas, Camanducaia, Campos Altos, Capela Nova, Carandaí, Carmo da Mata, Carvalho, Casa Grande, Catas Altas, Coluna, Conceição do Mato Dentro, Conselheiro Lafaiete, Conselheiro Pena, Corinto, Cristiano Otoni, Cruzília, Datas, Diamantina, Divinésia, Divinópolis, Dom Cavati, Dom Silvério, Dores de Guanhães, Dores de Indaiá, Entre Rio de Minas, Ervália, Estrela do Indaiá, Formiga, Funilândia, Furnas, Gouveia, Guapé, Guaranézia, Guarani, Ipatinga, Itabirito, Itaúna, Jenipapo de Minas, Joanésia, Juiz de Fora, Lagoa da Prata, Lima Duarte, Machado, Maria da Fé, Martinho Campos, Mátipo, Minduri, Nepomuceno, Novo Cruzeiro, Ouro Branco, Pará de Minas, Passa Quatro, Paula Candido, Pedro Leopoldo, Piedade dos Gerais, Piracema, Poços de Caldas, Pompeu, Ponte
} 
Quadro 1 - Cursos oferecidos pela Coordenação de Extensão em parceria com o SENAR, com a EMATER e com sindicados rurais.

\begin{tabular}{l:ll} 
& \multicolumn{1}{c}{ Cursos } & \\
Apicultura & Cestaria e trançados & Melado e rapadura \\
\hline Aplicação de defensivos & Conservas vegetais, compotas, frutas & Nutrição e alimentação \\
\hline Arborização & Derivados do leite & Olericultura básica / mod. I \\
\hline Artesanato em cestaria & Doces & Olericultura básica / mod. II \\
\hline Artesanato em argila & Doma racional em equídeos & Orquídeas \\
\hline Artesanato em rendas & Embutidos e defumados & Paisagismo \\
\hline Artesanato em tecidos & Equitação & Panificação \\
\hline Avicultura de corte & Horta orgânica & Pintura em tecidos \\
\hline Beneficiamento primário de plantas & Inseminação artificial & Piscicultura \\
\hline medicinais & Jardineiro & Plantas ornamentais \\
\hline Bordados & Laticínios & Plantas medicinais \\
\hline Bovinocultura de leite & Manutenção de motosserra & Pomar caseiro \\
\hline Bovinos - alimentação & Máquinas agrícolas & \\
\hline Casqueamento & & Saúde reprodutiva \\
\hline
\end{tabular}

(Fonte: pesquisa de campo, 2008).

Tais cursos são oferecidos conforme a demanda levantada pela CEDAF, pelos mobilizadores do SENAR e dos sindicados rurais. 0 contato da comunidade com a escola fica evidente no número de participantes nos cursos informais oferecidos via coordenação de extensão da CEDAF.

Tabela 2 - Forma como as solicitações da comunidade/sociedade são atendidas pela escola.

\begin{tabular}{l:c:c}
\hline $\begin{array}{l}\text { Concepção dos docentes sobre como } \\
\text { as solicitações de apoio técnico da } \\
\text { comunidade/sociedade são atendidas } \\
\text { pela escola }\end{array}$ & No & $\%$ \\
\hline $\begin{array}{l}\text { Percebe atendimento, contato da escola } \\
\text { com a comunidade }\end{array}$ & & 13 \\
\hline Não percebe atendimento & 81,25 \\
\hline
\end{tabular}

(Fonte: pesquisa de campo, 2008).

Nova, Presidente Kubitschek, Rio Casca, Rio Novo, Santa Maria do Suaçui, Santana da Vargem, Santana do Deserto, São João Del Rei, São João Evangelista, São José do Goiabal, São Miguel do Anta, São Vicente de Minas, Sapucaia, Senador Firmino, Sericita, Seritinga, Serranos, Sete Lagoas, Simonesia, Tarumirim, Timóteo, Tocantins, Turmalina, Uberaba, Uberlândia e Viçosa.
Apareceram várias respostas quanto à maneira como essas solicitações são atendidas. Porém, aquela que apareceu com maior frequência, em $40 \%$ dos casos, foi em relação aos cursos de extensão; na sequência, o contato direto com o produtor apareceu em 33,33\% das respostas. Os professores reconheceram haver influências indiretas, as quais acontecem quando eles estão ministrando cursos, quando fazem contatos com empresas, quando há demanda por novas tecnologias, como também pela evolução da área agropecuária. Podemos perceber que os professores levam para sua prática experiências pessoais que vão além do ambiente da escola e da sala de aula.

Foi possivel perceber que a CEDAF vem buscando parcerias para atender às demandas da sociedade. Porém, muitas dessas demandas atendidas pela escola não têm relação direta com o currículo do Curso Técnico em Agropecuária, mas sim com os contatos com os produtores rurais por meio de cursos de qualificação. 0 contato com instituições/ 
empresas parceiras da escola tende a influenciar nas mudanças currículares. Outro ponto que foi possivel observar é a busca por inserir questões ambientais no currículo.

\section{Consideraçōes finais}

Procuramos, neste artigo, compreender como se dá o processo de modificação do currículo do Curso Técnico em Agropecuária da CEDAF, quais são os atores nele envolvidos e como as modificações curriculares são incorporadas à prática de ensino dos professores.

Nossas hipóteses de investigação foram as seguintes:

1- os processos de modificação do currículo nas escolas agrotécnicas dão-se a partir dos direcionamentos legais.

2- os processos de modificação do currículo nas escolas agrotécnicas dão-se a partir da prática cotidiana dos professores;

3- os processos de modificação do currículo nas escolas agrotécnicas dão-se a partir das influências dos direcionamentos que emergem da sociedade;

4- os processos de modificação do currículo nas escolas agrotécnicas dão-se a partir da combinação entre os direcionamentos advindos da sociedade e da legislação, estando os professores condicionados a tais direcionamentos.

Nossa primeira hipótese, de que os processos de modificação do currículo nas escolas agrotécnicas dar-se-iam a partir dos direcionamentos legais, foi confirmada parcialmente. Apesar de os professores reconhecerem a existência dos Referenciais Curriculares Nacionais para a Educação Profissional, os quais norteiam a composição do currículo, eles não se orientam por esse documento na elaboração do plano de curso de suas matérias. Nota-se a força da lei interferindo na organização curricular do Curso Técnico em Agropecuária, principalmente em relação à carga horária. Outro ponto marcante da força da legislação é quanto aos temas/matérias trabalhados no curso, os quais demonstraram ter sofrido poucas alterações, uma vez que o Parecer $n^{0} 45 / 72$, que fixou um mínimo de matérias a ser exigido pelo Curso Técnico em Agropecuária, vigorou por 27 anos, ou seja, em quase a totalidade do tempo de oferecimento do curso. Mas o que causou mais impacto no currículo em relação à legislação foi a diminuição da carga horária da parte profissional do curso na última reforma de ensino, pela implantação da Lei ${ }^{\circ}$ 9.394/96. Na verdade, aumentou-se a carga horária do curso médio, ocasionando a diminuição da carga horária da parte profissionalizante.

A segunda hipótese, de que os processos de modificação do currículo nas escolas agrotécnicas dar-se-iam a partir da prática cotidiana dos professores, foi confirmada. Apesar de um currículo prescrito pela legislação, bem como norteado pelos Referenciais Curriculares, foi possivel perceber que ocorreram diversas influências sobre sua composição. 0s professores destacaram-se como agentes ativos nesse processo de mudanças, demonstrando ter espaço de autonomia para selecionar e alterar os conteúdos de suas matérias com base em sua prática cotidiana. Outros agentes importantes nesse processo são os alunos, pois a diversidade das realidades dos estudantes recebidos pela escola enriquece a troca de informações entre professor e aluno que ocorre no cotidiano do curso. A diversidade de interesses faz com que apareçam novas demandas na sala de aula, as quais muitas vezes não eram abordadas pelos professores. Os relatórios de estágio dos alunos ao final do curso também servem como um feedback para os professores, que reavaliam a formação e as necessidades de alterações e inovações no currículo.

Há, por parte dos professores, uma preocupação em manter os conteúdos das matérias sempre atualizados, levando em consideração o mercado de trabalho, a política agrícola, as inovações tecnológicas, as demandas de empresas, as demandas dos participantes de cursos 
informais (produtores rurais), as demandas dos alunos e a interlocução com profissionais de outras instituições. Portanto, os professores estão constantemente em contato com os alunos, com o mercado e com a sociedade, percebendo as necessidades de cada uma dessas instâncias e ajustando sua prática cotidiana à realidade que é por eles percebida. Os professores são decisivos na concretização dos conteúdos e significados curriculares. Eles são agentes ativos na configuração do currículo, fazendo com que sejam incorporadas demandas de diversos segmentos da sociedade. Portanto, conforme afırmou Sacristán (2000), diferentemente de qualquer currículo prescrito, o currículo realizado diz da diversidade prática do cotidiano da escola. Cada escola, cada professor, cada aluno e cada sala de aula manifestam diferentes interesses, a partir dos quais os currículos reais complementam-se e articulam-se em diferentes aspectos.

Quanto à terceira hipótese, de que os processos de modificação do currículo nas escolas agrotécnicas dar-se-iam a partir das influências dos direcionamentos que emergem da sociedade, consideramos que também pôde ser confirmada em nosso estudo, mesmo que essa influência da sociedade tenha aparecido de forma indireta nas entrevistas. Foi possível perceber, pelas atas das reuniões, a participação da sociedade nas decisões da CEDAF; exemplos claros disso foram a criação do Curso Técnico em Florestas, do Curso de Pedagogia e as diversas parcerias estabelecidas pela CEDAF para atender à sociedade.

As solicitações de apoio técnico e o atendimento a essa demanda também demonstraram a sociedade influenciando no currículo, uma vez que, segundo os professores, essas solicitações incidem sobre o conteúdo de suas matérias. A diversificação na oferta de cursos pela escola também pode ser entendida como uma demanda da sociedade, buscando um atendimento às novas configurações do meio rural, não mais exclusivamente agrícola.
Portanto, percebemos a sociedade participando das mudanças curriculares por intermédio dos próprios professores que com ela interagem em diversos eventos, por meio dos cursos de extensão e dos atendimentos técnicos. Essas demandas, conforme analisadas nos documentos pesquisados e nas entrevistas com os professores, partem de diversos segmentos da sociedade, tais como: produtores rurais, empresas, cooperativas, sindicatos, prefeituras, associações e alunos. Os dados coletados na pesquisa indicam-nos que a escola tem cumprido um importante papel quanto aos atendimentos das demandas advindas da sociedade, em conjunto com seus parceiros, atendendo a um público significativo nos cursos informais, como também abrangendo várias regiões do Estado de Minas Gerais.

Em nossa pesquisa, também identificamos que, apesar de a história e a política educacional da educação agrícola apresentarem-se como procedentes dos poderes hegemônicos presentes em diferentes governos, valorizando o desenvolvimento econômico, há a preocupação de atualização dos conhecimentos relativos às questões ambientais e de uma mudança no perfil de formação do técnico. Tal mudança iniciou-se como uma formação de mão de obra preparada para executar ordens e implementar pacotes tecnológicos; atualmente, busca alcançar, conforme Moreira (2005), uma formação na qual o técnico não é mais um ser social neutro e portador da verdade sobre a realidade do mundo. Embora hoje se busque uma formação de profissionais e cientistas flexíveis, críticos e responsáveis, nossos dados apontam para uma formação muito tradicional do técnico em agropecuária.

Portanto, nossa quarta hipótese, que é uma combinação das três anteriores, confirma-se, pois, conforme apresentado, os processos de modificação do currículo nas escolas agrotécnicas dão-se a partir da combinação entre os direcionamentos advindos 
da sociedade e da legislação. Os professores estão condicionados a esses direcionamentos, pois percebemos o currículo do Curso Técnico em Agropecuária como um campo de atividade de múltiplos agentes, em que forças se expressam em sua formatação; conforme afırma Sacristán (2000), "como algo construído no cruzamento de influências e campos de atividades diferenciados e inter-relacionados" (p. 104).

Assim, podemos afirmar que a concepção teórica adotada neste trabalho - a qual compreende o currículo, primeiro, como uma configuração e não como algo dado, e, segundo, como um campo de forças dentro do qual os desequilíbrios entre os atores envolvidos em sua configuração estabelecem-se mediante a incontestabilidade da realidade sustenta-se. Ou seja, não é possível nem que o Estado imponha leis que não possam ser operacionalizadas, nem que a escola desconheça as mudanças advindas da sociedade e do Estado, nem que a sociedade deixe de adequar-se a esses novos direcionamentos. Portanto, podemos afirmar a ideia do currículo como algo dinâmico, pulsante e não como um quadro ou documento para constar. 0 currículo é um instrumento que baliza a construção do profissional.

Este trabalho de pesquisa sobre o currículo da CEDAF é um recorte do universo possivel de estudo das escolas agrotécnicas. Há uma diversidade de possibilidades de pesquisas a serem desenvolvidas. Entre elas, o acompanhamento dos egressos é um desafio a ser vencido pelas escolas agrotécnicas para que se possam ter parâmetros para avaliar a formação oferecida por elas.

\section{Referências}

ALVES, N. (Org.). Criar currículo no cotidiano. São Paulo: Cortez, 2002.

APPLE, M. W. Política cultural e educação. São Paulo: Cortez, 2000.

BRASIL. Conselho Federal de Educação. Parecer n 45/72, de 12 de janeiro de 1972. Fixa os mínimos a serem exigidos em cada habitação profissional ou conjunto de habilitações afins no ensino do $2^{\circ}$ grau. Diário Oficial da União, Brasília, 1972.

BRASIL. Ministério da Educação. Lei ñ 9.394, de 20 de dezembro de 1996. Estabelece as diretrizes e bases da educação nacional. Diário Oficial da União, Brasília, 1996.

BRASIL. Resolução CNE/CEB nº 04/99, de 5 de outubro de 1999. Institui as diretrizes curriculares nacionais para a educação profissional de nível técnico. Diário Oficial da União, Brasília, 1999.

FORQUIN, J. C. Escola e cultura: as bases sociais e epistemológicas do conhecimento escolar. Porto Alegre: Artes Médicas, 1993.

MOREIRA, A. F. B.; SILVA, T. T. Sociologia e teoria crítica do currículo: uma introdução. In: MOREIRA, A. F. B.; SILVA, T. T. (Orgs.). Currículo, cultura e sociedade. 2. ed. São Paulo: Cortez,1995. p.7-37.

MOREIRA, J. R. Natureza, ciência e saberes I: Identidade social e técnico em agropecuária. Texto de apoio do Curso de Atualização para Técnicos da ATENS. Convênio CPDA/REDES - NEAD/INCRA. 2005. 
SACRISTÁN, J. G. Currículo e diversidade cultural. In: SILVA, T. T.; MOREIRA, A. F. (Orgs.). Territórios contestados. Petrópolis: Vozes, 1995. p. 82-113.

0 currículo: uma reflexão sobre a prática. 3. ed. Porto Alegre: Artmed, 2000.

SILVA, T. T. Currículo, conhecimento e democracia: as lições e as dúvidas de duas décadas. Cadernos de Pesquisa, n. 73, p. 59-66, 1990.

. Documentos de identidade: uma introdução às teorias do currículo. 2. ed. Belo Horizonte: Autêntica, 2007.

Recebido em 06.04.10

Aprovado em 13.09.10

Flávia Moreira Barroca de Barros é mestre em Extensão Rural pelo Departamento de Economia Rural da Universidade Federal de Viçosa.

Ana Louise de Carvalho Fiúza é doutora em Desenvolvimento, Agricultura e Sociedade pela Universidade Federal Rural do Rio de Janeiro, e professora do Departamento de Economia Rural da Universidade Federal de Viçosa.

E-mail: louisefiuza@ufv.br.

Maria de Lourdes Mattos Barreto é doutora em Desenvolvimento Humano e Educação pela Universidade Estadual de Campinas, e professora do Departamento de Economia Doméstica da Universidade Federal de Viçosa. E-mail: mmattos@ufv.br.

José Ambrósio Ferreira Neto é doutor em Desenvolvimento, Agricultura e Sociedade pela Universidade Federal Rural do Rio de Janeiro, e professor do Departamento de Economia Rural da Universidade Federal de Viçosa. E-mail: ambrosio@ufv.br. 